
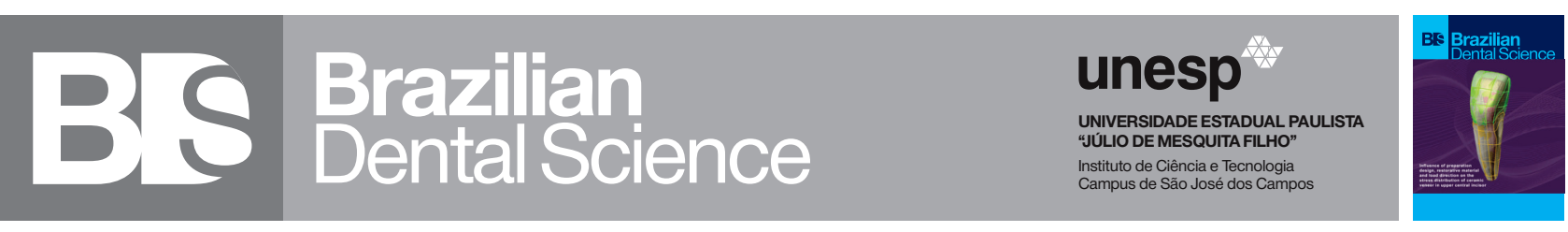

\title{
One Year Clinical Evaluation of Milled BioHPP Polyetheretherketone (PEEK)-Based versus Metal Ceramic Single Crowns (Randomized Controlled Clinical Trial)
}

Avaliação Clínica de um Ano de Coroas Fresadas à Base de Biohpp Polieteretercetona (PEEK) Versus Coroas Metalocerâmicas Unitárias (Ensaio Clínico Controlado Randomizado)

AbdelRahman BADRAN ${ }^{1}$, Amina ZAKI ${ }^{1}$, Karim RABIE ${ }^{1}$

1 - Faculty of Dentistry, Cairo University, Cairo, Egypt.

\section{ABSTRACT}

Objective: To evaluate the clinical behavior of milled BioHPP PEEK copings veneered with Visio.lign composite resin in comparison with metal copings veneered with feldspathic porcelain as single posterior crowns. Material and Methods: Twenty Four full coverage posterior crowns were fabricated for endodontically treated molars divided into 2 groups according to the material used. Twelve milled BioHPP PEEK-based crowns (Group 1) and Twelve Porcelain Fused to Metal (PFM) crowns (Group 2). The preparations were standardized with an equi-gingival, deep chamfer finish line for all teeth. BioHPP PEEK and metal copings were fabricated by CAD/CAM technology and lost wax technique respectively. These coping were veneered according to manufactures instructions either by special composite resin or low fusing glass ceramic respectively. The restorations were cemented then clinical evaluation of these crowns was assessed regarding mechanical failure, marginal integrity and patient satisfaction every two months for one year. Results: Although two PEEK crowns were fractured, both PEEK and PFM crowns showed similar fracture (mechanical failure) and marginal integrity without significant difference $(\mathrm{p}>0.05)$. BioHPP PEEK-based crowns showed statistically significantly lower patient satisfaction than PFM crowns

\section{RESUIMO}

Objetivo: Avaliar o comportamento clínico de copings fresados de BioHPP PEEK com cobertura de resina composta Visio.lign em comparação com copings metálicos cobertos com cerâmica feldspática em coroas unitárias posteriores. Material e Métodos: Vinte e quatro coroas totais posteriores de foram confeccionadas para molares tratados endodonticamente e divididos em 2 grupos de acordo com o material utilizado. Doze coroas fresadas à base de BioHPP PEEK (Grupo 1) e doze coroas de porcelana fundida ao metal (PFM) (Grupo 2). Os preparos foram padronizados para todos os dentes com término de chanfro largo ao nível gengival. BioHPP PEEK e os copings metálicos foram fabricados por tecnologia CAD/CAM e técnica da cera perdida, respectivamente. A aplicação da cobertura sobre os copings foi realizada de acordo com as instruções do fabricante, por resina composta especial ou cerâmica vítrea de baixa fusão, respectivamente. As restaurações foram cimentadas e a avaliação clínica dessas coroas foi realizada quanto à falha mecânica, integridade marginal e satisfação do paciente a cada dois meses durante um ano. Resultados: Embora duas coroas de PEEK tenham sido fraturadas, ambas as coroas de PEEK e PFM apresentaram fraturas semelhantes (falha mecânica) e integridade marginal sem diferença significativa $(p>0,05)$. As coroas à base de BioHPP PEEK mostraram uma satisfação do paciente significativamente menor do que as coroas PFM após seis meses (valor de $\mathrm{p}=0,013$; tamanho do efeito $=1,157$ ), mas todos os pacientes 
after six months (p-value $=0.013$, Effect size $=1.157$ ) but all the patients were generally satisfied. Conclusion: BioHPP PEEK-based crowns showed clinically similar and accepted mechanical behavior and marginal integrity but less patient's satisfaction than PFM crowns after six months. So BioHPP PEEK-based crowns may be used as an alternative tooth-colored metal-free fixed restoration for one year.

\section{KEYWORDS}

BioHPP; Metal ceramic; Patient satisfaction; PEEK; PFM. estavam geralmente satisfeitos. Conclusão: As coroas à base de BioHPP PEEK, em comparação às coroas PFM, mostraram desempenho clínico similar, aceitável comportamento mecânico e integridade marginal, mas menos satisfação do paciente, após seis meses. Portanto, as coroas à base de BioHPP PEEK podem ser utilizadas como uma alternativa de restauração livre de metal semelhante à cor do dente, por um ano.

\section{PALAVRAS-CHAVE}

BioHPP; Ligas Metalo-Cerâmicas; Satisfação do paciente; PEEK; Porcelana fundida ao metal.

\section{INTRODUCTION}

$\mathrm{D}$ ental technology is the science and art of designing and making medical oral devices that restore function and improve esthetic appearance. The different types of appliances can be classified by the type of materials used as polymers, metals or ceramics. An ideal restoration that mimics the natural tooth's appearance, longevity and durability is always the aim of dental professionals [1].

The Porcelain Fused to Metal (PFM) system is still widely used to fabricate crowns and fixed partial dentures and is considered as the gold standard treatment in dentistry. It combines the good mechanical properties, clinically acceptable marginal and internal adaptation in addition to satisfactory esthetic results [2]. It has high survival rate reaching $97 \%$ over seven years or more but many studies concluded that metal ceramic restorations exhibit porcelain veneer and metal framework fracture [3-4] in addition to high prevalence of allergy to many metal elements as nickel, palladium, cobalt and chromium. So esthetic concerns have stimulated the development of new dental tooth-colored systems as polymers [5].

Polyetheretherketone (PEEK) is a synthetic, tooth colored polymeric material that has been used as a biomaterial in many medical and dental applications [6]. It can be modified easily by incorporation of other materials as carbon fibers, glass fibers or ceramic fillers [7].

Biocompatible High Performance Polymer (BioHPP) PEEK is 20\% ceramic reinforced, semicrystalline, thermoplastic and radiolucent. It is characterized by low density, light weight, shock absorber, biocompatible and can be veneered with composite resin [8]. It is used for fabrication of frameworks for fixed and removable dental prostheses. BioHPP PEEK can be fabricated via CAD/CAM technology by milling PEEK blanks. It is also can be pressed by using granular or pellet-shaped PEEK. Such unique physical and mechanical properties may promote the BioHPP PEEK to be considered as a promising material for dental application [6].

Therefore, the hypothesis of this study stated that milled BioHPP PEEK-based single crowns would offer better clinical performance and patient satisfaction compared to metal ceramic crowns.

\section{MATERIAL AND METHODS}

\section{Ethical considerations and approval}

This randomized clinical trial was conducted in the Department of Fixed Prosthodontics in Faculty of Dentistry, Cairo University. The ethical approval for the study was obtained from the Ethics Committee of Scientific Research - Faculty of Dentistry - Cairo 
University (approval no: 181040). Participation in the study was voluntary and informed consent was obtained from all of them before starting the treatment regarding treatment sequence, publishing of their images and results.

\section{Registration}

This trial was registered at the Clinical Trials.gov registry under registration number NCT03685513 on September 26, 2018.

\section{Study design}

This study was a double blind randomized controlled clinical trial with a 1:1 allocation ratio.

\section{Sample size estimation}

Based on data from previously published studies, the sample size was 22 endodontically treated molar teeth obtained with $80 \%$ power and at 5\% significance. using a power analysis. Sample size calculation was performed using G*Power Version 3.1.9.2 [9]

\section{Participant's selection}

All participants fulfilled the following inclusion criteria: 1 . patients with at least one successful endodontically treated molar tooth; 2 . their ages ranged from 18 to 50 years; 3 . absence of parafunctional habits; 4. they had good oral hygiene and no periodontal diseases; 5 . They had canine guided occlusal scheme and no deep bite. They were recruited during the time from January 2019 till July 2019 from the outpatient clinic of Fixed Prosthodontics Department, Faculty of Dentistry, Cairo University, Cairo, Egypt. Screenings of patients were carried out until target number was reached. This study was completed by August 2020. Full medical and dental history was obtained from all participants.

\section{Allocation concealments}

In each group number for each member was written by indispensable pen on large white paper sheet. The sheet was folded eight times and saved inside opaque well sealed envelope.

\section{Implementation}

The candidate under supervision was responsible for providing allocation generation and dividing patients into two groups and save it in the envelopes in secured place until the date of performing procedure.

\section{Randomization}

Randomization was carried out using computerized sequence generation (https:// www.randomizer.org) in the Center of Evidence Based Dentistry, Cairo University. Participants were assigned in two groups ( 1 or 2 ) according to the material type of the restoration received. Each participant received a sealed opaque envelope with their randomized number. Group (1) received BioHPP PEEK single posterior crowns while group (2) received PFM single posterior crowns.

\section{Table I - Sample grouping}

\begin{tabular}{|c|c|c|}
\hline $\begin{array}{c}\text { Group (1) } \\
\text { Intervention group }\end{array}$ & $\begin{array}{c}\text { Group (2) } \\
\text { Control group }\end{array}$ & $\begin{array}{c}\text { Total number of } \\
\text { crowns }\end{array}$ \\
\hline $\begin{array}{c}\text { BioHPP PEEK crowns } \\
(n=12)\end{array}$ & $\begin{array}{c}\text { PFM crowns } \\
(n=12)\end{array}$ & $(n=24)$ \\
\hline
\end{tabular}

\section{Blinding}

The outcome assessors (prosthodontist colleagues) and the participants were blind (double blinding) to the material while the operator (the researcher) will not due to the difference in restorative material presentation and application protocol.

\section{Intervention}

Two different materials (BioHPP PEEK copings veneered with Visio.lign composite resin and nickel-chromium metal copings veneered with low fusing porcelain) were selected for fabrication of single posterior crowns for this study. All treatment procedures were performed by the same clinician. The prosthodontics procedures were performed into 3 visits in the clinics of Fixed Prosthodontics Department, Faculty of Dentistry, Cairo University, Cairo, Egypt. 


\section{Visit 1}

It started with taking personal, medical and dental history followed by clinical examination for assessment of remaining tooth structure, occlusal scheme, periodontal condition, oral hygiene, dental caries and parafunctional habits. Then radiographic examination was done to assess the quality of the endodontic treatment, alveolar bone level and crown/root ratio. Scaling and polishing were performed for each patient in order to improve the oral hygiene level and allow accurate shade selection. Intraoral pre-operative photographs were taken for documentation of the cases. (Figure 1). Finally a silicone putty (Zhermack, Elite ${ }^{\circledR}$ HD + Putty soft, fast set, Italy) index was taken for the provisional restoration involving at least one tooth beyond the tooth to be restored, if the tooth was broken down, adjustments with inlay wax were done before the index was taken.
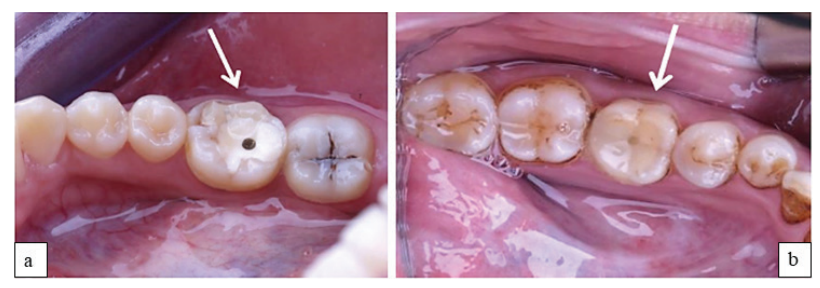

Figure 1 - Representative pre-operative photos of each investigated group a. A case of group (1) b. A case of group (2).

\section{Visit 2}

Standardized teeth preparations were done with the aid of orientation grooves on the occlusal, buccal and lingual surfaces to produce $1 \mathrm{~mm}$ equigingival deep champher finish line with 1-1.5 mm axial reduction and $1.5-2 \mathrm{~mm}$ occlusal reduction [10]. All sharp line angles that might serve as a point for stress concentration were rounded. Functional cusp bevel was performed with 45o to the long axis of the functional cusps. (Figure 2) A retraction cord (AtriaPak, South Korea) was used to allow accurate impression making. Final impressions were taken using Polyvinyl siloxane (PVS) addition silicon (Ghenesyl, Lascod, Italy) in plastic stock trays with two steps impression technique [11].
To fabricate provisional crowns, the silicone index was filled with bis-acrylate resin composite material (Cooltemp, coltene, Switzerland) and placed on the lubricated teeth intra-orally. After setting, the temporary restoration was finished, polished and temporary cemented using non-eugenol, acrylic-urethane polymer based temporary cement (RelyX Temp NE, 3MESPE, USA) [12].

Once the dental laboratory received the final impression, the master cast was poured with a type IV dental stone according to manufacturer's instruction to produce the master cast.

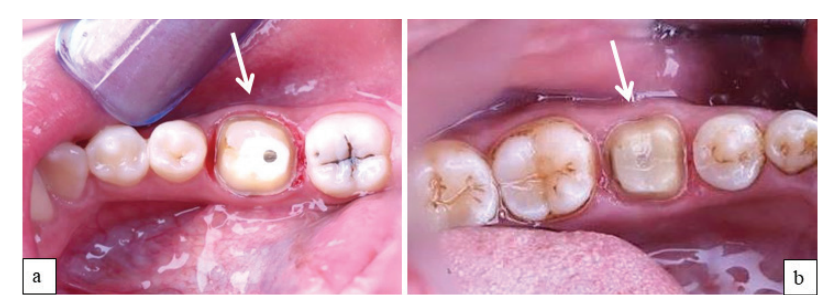

Figure 2 - Representative preparation photos of each investigated group a. A case of group (1) b. A case of group (2).

\section{Construction of BioHPP PEEK crowns}

An extra-oral scanner (InEos X5, Cerec, Sirona) was used to scan the master cast and a three-dimensional image was obtained for abutment tooth on the computer screen. Using Exocad software (Exocad software, Exocad $\mathrm{GmbH}$, Germany), designing of the BioHPP PEEK copings was done. BioHPP PEEK was supplied in the form of a blank which was milled to fabricate tooth shape supported copings by CAD/CAM technology.

Conditioning of the copings was done by blasting (basic Quattro IS; Renfert, Hilzingen, Germany) them with $110 \mu \mathrm{m} \mathrm{Al} 2 \mathrm{O} 3$ powder at $0.25 \mathrm{MPa}$ and 2-3 bar pressure at an angle of $45^{\circ}$ from a distance of $10 \mathrm{~mm}$, [13] and subsequently put in an ultrasonic bath for 5 min which was filled with deionized water. Afterwards, Visio. link primer was applied and immediately polymerized for 90 seconds by a special light polymerization device (Brelux Power Unit 2, 
Bredent, Germany) (wavelength: 370-500 nm, intensity: $220 \mathrm{~mW} / \mathrm{cm} 2$, with 72 LED lamps and temperature control of $45{ }^{\circ} \mathrm{C}-55{ }^{\circ} \mathrm{C}$ to prevent overheating).

Veneering of BioHPP PEEK copings started with application of dual-hardening combo.lign opaque as a first layer (wash opaquer) followed by crea.lign opaque on the BioHPP coping. They were polymerized for 180 seconds [14].

The body and the neck of the coping were coated with crea.lign dentin paste IV with maximum thickness of $1 \mathrm{~mm}$ to give the proper anatomy and contour to the crown. Then it was polymerized for 180 seconds.

The cusp tips and proximal surfaces were coated with Enamel EV to give the natural translucency to the crown. Then it was polymerized for 180 seconds.

Crea.lign modeling liquid was used during layering as it serves as modifier regarding viscosity and modulus of elasticity. After complete building up and light curing, crea. lign surface cleaner was used to remove the dispersion layer. The crown was characterized by Visio.paint stains and polymerized for 180 seconds.

Finally BioHPP PEEK crowns were polished using Acrypol polishing paste and Visio. lign polishing Kit. They ensure a perfect finish and surfaces with high plaque resistance and shade stability [14] (Figure 3a).

\section{Construction of PFM crowns}

This was done via lost wax technology including wax pattern fabrication which was immediately invested with phosphate-bonded investment material (Bellavest SH, BEGO, Germany). The wax elimination was carried out in the preheating oven at a temperature of 400 ${ }^{\circ} \mathrm{C}$ (20 min.). After complete burnout of the wax, the investment ring was preheated after setting. The burnout temperature reached $850{ }^{\circ} \mathrm{C}$ and left for $45 \mathrm{~min}$.

Suitable amount of I-BOND LO (Interdent d.o.o., Slovenia) nikel-chromium (Ni-Cr) metal ingots were selected for the respective wax weight for casting. Ni-Cr ingots were put into the melting crucible and then melting of these ingots was done. After the melting procedure, the molten metal was casted into the mold using a centrifugal casting machine.

After cooling to room temperature (approximately 60 minutes), divesting was performed with gentle and careful hammering and sprue was cut off. The fine investment material residues are removed using a fine blasting device with aluminum oxide with 50 $\mu \mathrm{m}$ max. 3 bar.

After metal copings construction, VMK Master (ViTA Zahnfabri, H.Rauter GmbJ \& Co.KG, Germany). low fusing porcelain was used to veneer them starting first by mixing the opaque powder with its special liquid to get the proper consistency then it was applied in two layers then fired in the porcelain furnace according to the manufacturer instruction; Preheating at 500 ${ }^{\circ} \mathrm{C}$ then raising the temperature gradually $80^{\circ} \mathrm{C} /$ min until reaching the final temperature $950{ }^{\circ} \mathrm{C}$ under vacuum with 1 minute holding time.

Then dentin powder followed by the enamel powder were mixed and applied over the opaque layer till reaching the desired anatomy and occlusion then fired according to the manufacturer's instruction; Preheating at 500 ${ }^{\circ} \mathrm{C}$ then raising the temperature gradually $55^{\circ} \mathrm{C} /$ min until reaching the final temperature $(930$ ${ }^{\circ} \mathrm{C}$ ) under vacuum with 1 minute holding time. Finally the crowns were self-glazed according to the manufacturer instructions without vacuum. (Figure 3b)

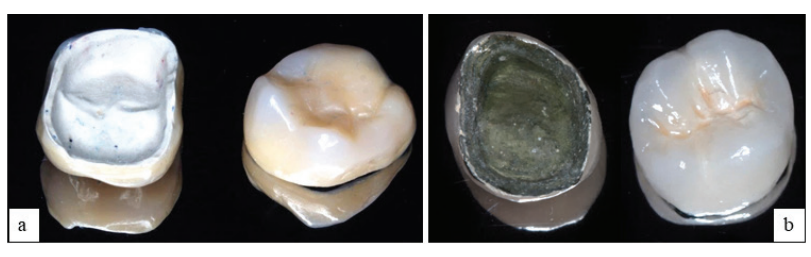

Figure 3 - Final Restoration a. BioHPP PEEK crown veneered with Visio.lign composite resin b. Metal ceramic crown.

\section{Visit 3}

The provisional crowns were removed and the teeth were polished to remove remnants of 
the provisional cements. The fitting surfaces of both groups were conditioned by blasting the restorations at 2 to 3 bar blasting pressure with aluminum oxide (110 $\mu \mathrm{m}$ and $50 \mu \mathrm{m}$ for the PEEK and PFM fitting surfaces respectively).

After isolation, all teeth surfaces were dried gently for 5 seconds. Then glass ionomer luting cement (Harvard Dental International $\mathrm{GmbH}$, Germany) was applied to the fitting surfaces of the crowns which were seated using finger pressure. Excess cement was removed using a sharp explorer and waxed dental floss. Varnish was applied on the margins using micro-brush to prevent initial solubility of the glass ionomer cement. Moreover, an articulating paper was used to check for any occlusal interference after setting. (Figure 4)

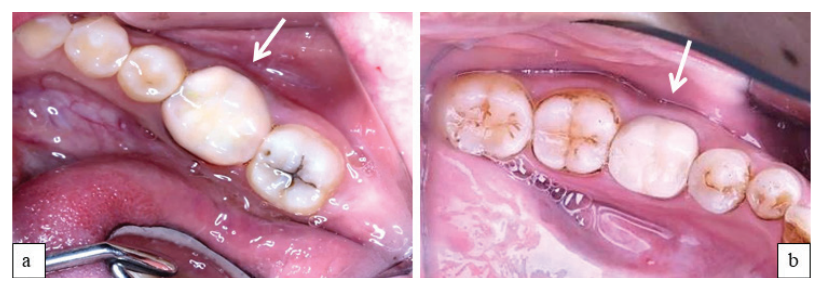

Figure 4 - Representative post-operative photos of each investigated group after cementation a. A case of group (1) b. A case of group (2).

\section{Postoperative instruction and care}

The patients were instructed not to eat on that side for 24 hours until complete setting of the glass ionomer luting cement. They were also instructed to perform brushing and flossing regularly using non-abrasive fluoridated tooth paste and soft brush.

\section{Follow up sessions}

Recall examinations were performed to all patients after $2,4,6,8,10$ and 12 months. During the examination, direct clinical evaluation was performed by the outcome assessors using modified Ryge criteria [15] for fracture (mechanical failure) and marginal integrity, in addition to evaluating the patients' satisfaction via a questionnaire [16].
Table II - Outcome measures, measuring device and measuring unit

\begin{tabular}{|cccc|}
\hline $\begin{array}{c}\text { Outcome } \\
\text { Measure }\end{array}$ & $\begin{array}{c}\text { Measuring } \\
\text { Method }\end{array}$ & $\begin{array}{c}\text { Measuring } \\
\text { Unit }\end{array}$ \\
\hline $\begin{array}{c}\text { Primary } \\
\text { 1ry }\end{array}$ & $\begin{array}{c}\text { Fracture (Mechanical } \\
\text { Failure) }\end{array}$ & $\begin{array}{c}\text { Modified Ryge } \\
\text { Criteria }\end{array}$ & Discrete (scores) \\
$\begin{array}{c}\text { Secondary } \\
\text { 2ry }\end{array}$ & $\begin{array}{c}\text { Marginal adaptation } \\
\text { Modified Ryge } \\
\text { Criteria }\end{array}$ & Discrete (scores) \\
\hline $\begin{array}{c}\text { Tertiary } \\
\text { 3ry }\end{array}$ & Patient satisfaction & $\begin{array}{c}\text { (Questionnaire) } \\
\text { Visual Analog Scale } \\
\text { (VAS) }\end{array}$ & $\begin{array}{c}\text { Numerical (discrete) } \\
\text { (from "0" unsatisfied } \\
\text {-to “10" satisfied) }\end{array}$ \\
\hline
\end{tabular}

\section{Statistical analysis}

Qualitative data were presented as frequencies and percentages. Fisher's Exact test was used to compare between the two groups. Friedman's test was used to study the changes by time within each group. Numerical data were explored for normality by checking the distribution of data and using tests of normality (Kolmogorov-Smirnov and Shapiro-Wilk tests). Data were presented as mean, standard deviation (SD), median and range values. For parametric data, Student's t-test was used to compare between mean values in the two groups. For non-parametric data, Mann-Whitney U test was used to compare between the two groups. Friedman's test was used to study the changes by time within each group. Dunn's test was used for pair-wise comparisons when Friedman's test is significant. The significance level was set at $\mathrm{P}$ $\leq 0.05$. Statistical analysis was performed with IBM SPSS Statistics for Windows, Version 23.0. Armonk, NY: IBM Corp.

\section{RESULTS}

\section{Fracture (Mechanical failure)}

5)

\section{A. Comparison between groups: (Figure}

Results of comparison between the two groups are presented in Table (III). Only 2 PEEK crowns showed occlusal spot fracture in the veneering composite resin after 6 and 10 months.

After 2 as well as 4 months; all restorations in the two groups showed (Alpha) score. 
After 6 and 8 months; $91.7 \%$ of restorations in PEEK group showed (Alpha) score and 8.3\% showed (Bravo) score. In PFM group; all restorations showed (Alpha) score. There was no statistically significant difference between the two groups (P-value $=1.000$, Effect size $=$ 0.478). (Figure 6a)

After 10 and 12 months; 83.3\% of restorations in PEEK group showed (Alpha) score and $16.7 \%$ showed (Bravo) score. In PFM group; all restorations showed (Alpha) score. There was no statistically significant difference between the two groups (P-value $=0.478$, Effect size $=$ 0.455). (Figure 6b)
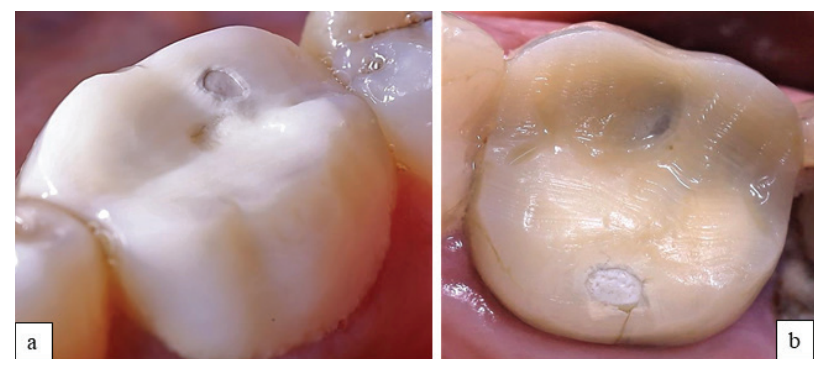

Figure 6 - Fractured PEEK crowns a. First fractured case after 6 months b. Second fractured case after 10 months.

Table III - Descriptive statistics and results of Fisher's Exact test for comparison between fracture scores in PEEK and PFM groups

\begin{tabular}{|c|c|c|c|c|c|c|}
\hline \multirow[t]{2}{*}{ Time } & \multicolumn{2}{|c|}{$\begin{array}{l}\text { PEEK } \\
(n=12)\end{array}$} & \multicolumn{2}{|c|}{$\begin{array}{l}\text { PEEK } \\
(n=12)\end{array}$} & \multirow[t]{2}{*}{$P$-value } & \multirow{2}{*}{$\begin{array}{c}\text { Effect } \\
\text { size } \\
\text { (OR) }\end{array}$} \\
\hline & n & $\%$ & n & $\%$ & & \\
\hline $\begin{array}{l}2 \text { months } \\
\text { Alpha }\end{array}$ & 12 & 100 & 12 & 100 & $\begin{array}{c}\text { Not } \\
\text { computed }\end{array}$ & \\
\hline $\begin{array}{l}4 \text { months } \\
\text { Alpha }\end{array}$ & 12 & 100 & 12 & 100 & $\begin{array}{c}\text { Not } \\
\text { computed }\end{array}$ & \\
\hline $\begin{array}{l}6 \text { months } \\
\text { Alpha }\end{array}$ & 11 & 91.7 & 12 & 100 & 1.000 & 0.478 \\
\hline Bravo & 1 & 8.3 & 0 & 0 & & \\
\hline $\begin{array}{l}8 \text { months } \\
\text { Alpha }\end{array}$ & 11 & 91.7 & 12 & 100 & 1.000 & 0.478 \\
\hline Bravo & 1 & 8.3 & 0 & 0 & & \\
\hline $\begin{array}{l}10 \text { months } \\
\text { Alpha }\end{array}$ & 10 & 83.3 & 12 & 100 & 0.478 & 0.455 \\
\hline Bravo & 2 & 16.7 & 0 & 0 & & \\
\hline $\begin{array}{l}12 \text { months } \\
\text { Alpha }\end{array}$ & 10 & 83.3 & 12 & 100 & 0.478 & 0.455 \\
\hline Bravo & 2 & 16.7 & 0 & 0 & & \\
\hline
\end{tabular}

\section{B. Changes within each group}

In PEEK group; there was no statistically significant change in fracture scores by time $(\mathrm{P}$-value $=0.186$, Effect size $=0.125)$. As regards PFM group, all specimens showed (Alpha) score through all follow-up periods.

\section{Marginal integrity}

All restorations in the two groups showed intact margin through all follow-up periods and showed (Alpha); so no statistical comparison was performed.

\section{Patient satisfaction}

7)

\section{A. Comparison between groups (Figure}

As regards the total satisfaction score; PEEK group showed statistically significantly lower median satisfaction score than PFM group $(\mathrm{P}$-value $=0.013$, Effect size $=1.157)$.

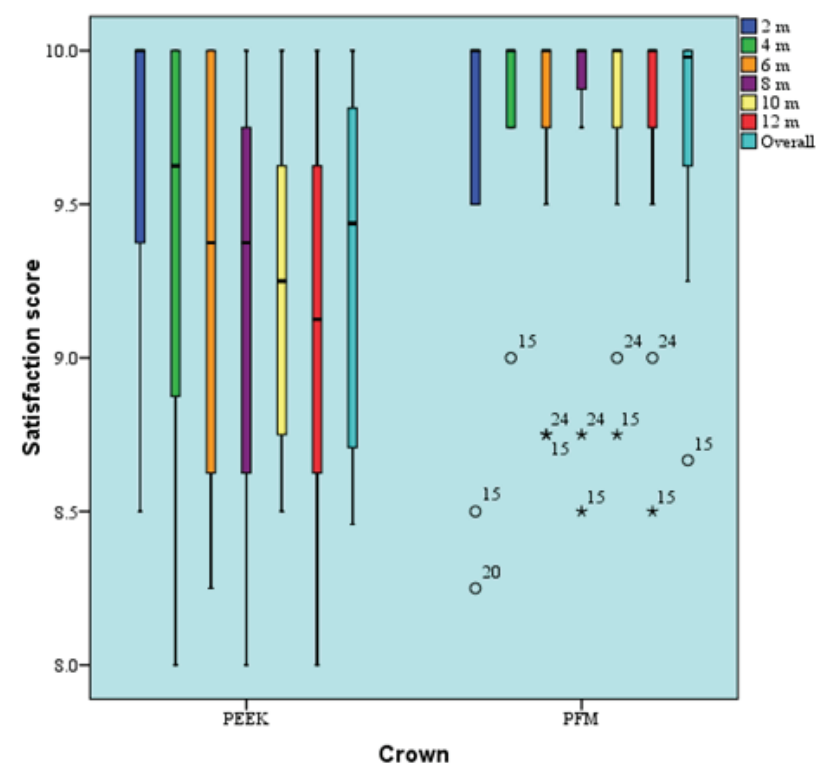

Figure 7 - Box plot representing median and range values for patient satisfaction scores in the two groups (Stars and circles represent outliers). 
Table IV - Descriptive statistics and results of Mann-Whitney $U$ test for comparison between patient satisfaction scores in PEEK and PFM groups

\begin{tabular}{|c|c|c|c|c|c|c|}
\hline \multirow{2}{*}{ Time } & \multicolumn{2}{|c|}{$\begin{array}{c}\text { PEEK } \\
(n=12)\end{array}$} & \multicolumn{2}{|c|}{$\begin{array}{c}\text { PEEK } \\
(n=12)\end{array}$} & \multirow{2}{*}{$p$-value } & \multirow{2}{*}{$\begin{array}{l}\text { Effect } \\
\text { size }(d)\end{array}$} \\
\hline & $\begin{array}{l}\text { Median } \\
\text { (Range) }\end{array}$ & $\begin{array}{l}\text { Mean } \\
\text { (SD) }\end{array}$ & $\begin{array}{l}\text { Median } \\
\text { (Range) }\end{array}$ & $\begin{array}{l}\text { Mean } \\
\text { (SD) }\end{array}$ & & \\
\hline 2 months & $10(8.5-10)$ & $9.6(0.5)$ & $10(8.3-10)$ & $9.6(0.6)$ & 0.974 & 0.012 \\
\hline 4 months & $9.6(8-10)$ & $9.3(0.7)$ & $10(9-10)$ & $9.9(0.3)$ & 0.088 & 0.671 \\
\hline 6 months & $9.4(8.3-10)$ & $9.3(0.7)$ & $10(8.5-10)$ & $9.8(0.5)$ & $0.040^{\star}$ & 0.829 \\
\hline 8 months & $9.4(8-10)$ & $9.2(0.7)$ & $10(8.5-10)$ & $9.8(0.5)$ & $0.012^{\star}$ & 1.121 \\
\hline 10 months & $9.3(8.5-10)$ & $9.2(0.7)$ & $10(8.8-10)$ & $9.8(0.4)$ & $0.005^{\star}$ & 1.310 \\
\hline 12 months & $9.1(8-10)$ & $9.1(0.6)$ & $10(8.5-10)$ & $9.8(0.5)$ & $0.005^{*}$ & 1.331 \\
\hline Overall & $9.4(8.5-10)$ & $9.3(0.6)$ & $10(8.7-10)$ & $9.8(0.4)$ & $0.013^{*}$ & 1.157 \\
\hline
\end{tabular}

*: Significant at $\mathrm{P} \leq 0.05$

\section{B. Changes within each group}

As regards PEEK group; there was a statistically significant change in patient satisfaction scores by time (p-value $=0.004$, Effect size $=0.285$ ). While in PFM group; there was no statistically significant change in patient satisfaction scores by time (p-value $=0.187$, Effect size $=0.125$ ).

\section{Survival analysis}

Since all restorations showed (Alpha) or (Bravo) scores in the two groups, then there were no failures and the survival of the two types of restorations was $100 \%$.

\section{DISCUSSION}

The Porcelain Fused to Metal (PFM) crowns were selected as they are considered as the gold standard treatment in dentistry but many studies concluded that they exhibit porcelain veneer and metal framework fracture in addition to high prevalence of allergy to many metal elements [34]. On the other hand BioHPP PEEK was used as the intervention group in this study as very little documentation is present regarding its clinical performance as fixed prostheses regarding fracture resistance, marginal integrity and patient satisfaction.

All the teeth included in this study were posterior molar teeth which aimed for standardization of the samples regarding teeth size, location and expected occlusal forces which would affect the outcome of the study.

The hypothesis of this study was rejected because the milled BioHPP PEEK-based single crowns offered statistically similar fracture resistance (mechanical failure) and marginal integrity not better than metal ceramic crowns. Also the PEEK crowns showed statistically significantly lower patient satisfaction than metal ceramic crowns especially after 6 months but all the patients were generally satisfied in both groups.

Regarding fracture (mechanical failure), there was no statistically significant difference between the 2 groups over the follow up year. All the PFM crowns survived with alpha score without any evidence of fractured veneering porcelain. On the other hand, 2 BioHPP PEEK crowns showed occlusal fracture of the veneering composite resin after 6 and 10 months. These fractures may be due to weak bond strength of PEEK framework to veneering composite resin, owing to its hydrophobic, chemically inert surface and its resistance to surface modifications by different chemical treatments. These fractures may be also due to low wear resistance of the veneering composite in comparison with the veneering porcelain in the PFM crowns or presence of occlusal prematurities or interferences in centric or eccentric occlusion.

This might be in accordance with Nazari et al. in 2016 [17] and Taufall et al. in 2016 [18] who found that the failure mode of all PEEK restorations was adhesive between the frameworks and the veneering composite. This was also in agreement with Sulaya and Guttal in 2020 [10] who suggested that the cause of the PEEK fracture may be due to localized biting forces, premature contact. Contradictory to these results, Jin et al. in 2019 found that no chipping occurred for the veneering composite over BioHPP PEEK frameworks.

Regarding marginal integrity, there was no statistical significant difference between the 2 groups over the follow up year. All the crowns 
in the 2 groups showed excellent marginal integrity scoring alpha score in all follow up visits within the year. This may be due to good marginal adaptation between the restoration and tooth margins as a result of accurate fabrication procedures whether by lost wax technique in the PFM crowns or milling in the PEEK crowns.

This was in agreement with Attia and Shokry in 2020, [8] Sulaya and Guttal in 2020 [10] and Abdullah et al. in 2016 [19] who found that milled PEEK crowns showed good marginal precision which was clinically satisfactory (45 \pm 6 $\mu \mathrm{m})$. This is was also in accordance with Jin et al. in 2019 [20] and Hossam et al. in 2018 [21] who found milled BioHPP PEEK frameworks veneered with composite resin having good marginal fit $(20 \pm 4 \mu \mathrm{m})$.

Regarding patient satisfaction, although PEEK group showed statistically significantly lower median satisfaction score than PFM group $($ P-value $=0.013$, Effect size $=1.157)$ especially after 6 months, but all the patients in both groups were generally satisfied with their restorations. These results might be reasonable due to the 1 year duration of this study. So more studies with longer durations are required to get more accurate results. Some patients in the PEEK group complained of color change in their PEEK crowns after 6 months which was confirmed by the outcome assessors. They said that the color become darker than the initial color at delivery time. This might be due to the hydrophilic resin nature of the veneering composite which permits water and beverages sorption leading to darkening of the restoration color.

This was in agreement with Lee et al. in 2007 [22] who concluded that nano-filled composite demonstrated the highest staining because of 2 reasons. The first reason is due to the hydrophilicity of the resin matrix. The second reason is due to the porosity in the aggregated fillers of the composite resin. Meanwhile, glass ceramics are more resistant to discoloration than composite resin materials as stated by Bahadır et al. in 2020. [23] This is also in accordance with Sulaya and Guttal in 2020 [10] after evaluation of patients' satisfaction of 20 PEEK crowns via questionnaire. They found $50 \%-60 \%$ of the participants had given a score of 5 (excellent) and around 20\%-30\% scored it at 4 (good) and around $10 \%-20 \%$ scored it at 3 (average). Zoidis and Papathanasiou in 2016 [24] found that PEEK provides high patient satisfaction and comfort during function because of its insolubility and low reactivity with other materials. PEEK could be suitable for patients allergic to metals or sensitive to metallic taste. In addition, the white color of the PEEK framework in combination with the veneering composite resins eliminates the grayish appearance of metal frameworks, providing a metal-free highly esthetic outcome.

\section{Limitations}

Further long term studies with more sample size and longer follow up period are required to evaluate clinical performance and patients' satisfaction of both restorations and to investigate whether BioHPP survival is time dependent.

\section{CONCLUSION}

Within the limitations of this study, the following conclusion and recommendations could be drawn as follows:

1. Both BioHPP PEEK and PFM crowns showed statistically similar and clinically accepted fracture resistance (mechanical failure) and marginal integrity.

2. BioHPP PEEK single posterior crowns generally showed accepted patient satisfaction in one year but less than PFM crowns especially after six months.

3. BioHPP PEEK crowns may be used as an alternative tooth-colored metal-free fixed restoration as single posterior crowns for one year.

\section{Acknowledgments}

The authors are grateful to the staff members of Fixed Prosthodontic Department, Faculty of Dentistry, Cairo University for content contribution, their critical review of the 
manuscript and support during the development and writing of this manuscript.

\section{Funding}

This study was self-funded

\section{Conflict of interest}

The authors have no proprietary, financial, or other personal interest of any nature or kind in any product, service, and/or company that is presented in this article.

\section{Regulatory Statement}

This study was conducted in accordance with all the provisions of the local human subject's oversight committee guidelines and policies of: the Ethics Committee of Scientific Research - Faculty of Dentistry - Cairo University. The approval code for this study is: 181040 .

\section{REFERENCES}

1. RRueggeberg FA. From vulcanite to vinyl, a history of resins in restorative dentistry. J Prosthet Dent. 2002 Apr;87(4):364-79. doi:10.1067/ mpr.2002.123400.

2. Martins LM, Lorenzoni FC, Melo A0, Silva LM, Oliveira JL, Oliveira PC, et al. Internal fit of two all-ceramic systems and metal-ceramic crowns. J Appl Oral Sci. 2012 Mar-Apr;20(2):235-40. doi: 10.1590/s167877572012000200019 .

3. Anusavice KJ. Standardizing failure, success, and survival decisions in clinical studies of ceramic and metal-ceramic fixed dental prostheses. Dent Mater.2012 Jan;28(1):102-11. doi:10.1016/j.dental.2011.09.012.

4. Pang Z, Chughtai A, Sailer I, Zhang Y. A fractographic study of clinically retrieved zirconia-ceramic and metal-ceramic fixed dental prostheses. Dent Mater. 2015 0ct;31(10):1198-206. doi: 10.1016/j.dental.2015.07.003.

5. Zhang X, Wei LC, Wu B, Yu LY, Wang XP, Liu Y. A comparative analysis of metal allergens associated with dental alloy prostheses and the expression of HLA-DR in gingival tissue. Mol Med Rep. 2016 Jan;13(1):91-8. doi:10.3892/ mmr.2015.4562.

6. Najeeb S, Zafar MS, Khurshid Z, Siddiqui F. Applications of polyetheretherketone (PEEK) in oral implantology and prosthodontics. J ProsthodontRes. 2016 Jan;60(1):12-9. doi:10.1016/j.jpor.2015.10.001.

7. Lee WT, Koak JY,Lim YJ, Kim SK, Kwon HB, Kim MJ. Stress shielding and fatigue limits of poly-ether-ether-ketone dental implants. J Biomed Mater Res B Appl Biomater. 2012 May;100(4):1044-52. doi: 10.1002/jbm.b.32669.

8. Attia MA, Shokry TE. Effect of different fabrication techniques on the marginal precision of polyetheretherketone single-crown copings. J Prosthet Dent. 2020 Nov;124(5):565.e1-565.e7. doi: 10.1016/j.prosdent.2020.04.003.
9. Prabhu R, Prabhu G, Baskaran E, Arumugam EM. Clinical acceptability of metal-ceramic fixed partial dental prosthesis fabricated with direct metal laser sintering technique-5 year follow-up. J Indian Prosthodont Soc. 2016 Apr-Jun;16(2):193-7. doi:10.4103/0972-4052.176526.

10. Sulaya K, Guttal SS. Clinical evaluation of performance of single unit polyetheretherketone crown restoration-a pilot study. J Indian Prosthodont Soc. 2020 Jan-Mar;20(1):38-44. doi:10.4103/jps.jps_228_19.

11. Al-Sayed HD, Al-Resayes SS, Jamjoom FZ, Al-Sowygh ZH. The effect of various core build-up materials on the polymerization of elastomeric impression materials. Saudi J Dent Res. 2013:4(2):71-5. doi:https://doi. org/10.1016/j.ksujds.2012.11.007

12. Chiluka L, Shastry YM, Gupta N, Reddy KM, Prashanth NB, Sravanthi K. An In vitro study to evaluate the effect of eugenol-free and eugenol-containing temporary cements on the bond strength of resin cement and considering time as a factor. J Int Soc Prev Community Dent. 2017 Jul-Aug;7(4):202-7. doi: 10.4103/jispcd.JISPCD_138_17.

13. Stawarczyk B, Beuer F, Wimmer T, Jahn D, Sener B, Roos M, et al. Polyetheretherketone-a suitable material for fixed dental prostheses? J Biomed Mater Res B Appl Biomater. 2013 0ct;101(7):1209-16. doi:10.1002/ jbm.b.32932.

14. Meshreky, M., Halim, C., Katamish, H. (2020). Vertical Marginal Gap Distance of CAD/CAM Milled BioHPP PEEK Coping Veneered by HIPC Compared to Zirconia Coping Veneered by CAD-On lithium disilicate "In-Vitro Study". Advanced Dental Journal, 2(2), 43-50. doi: 10.21608/adjc.2020.21032.1043

15. Raigrodski AJ, Yu A, Chiche GJ, Hochstedler JL, Mancl LA, Mohamed SE. Clinical efficacy of veneered zirconium dioxide-based posterior partial fixed dental prostheses: five-year results. J Prosthet Dent. 2012 0ct;108(4):214-22. doi: 10.1016/S0022-3913(12)60165-6.

16. Samer MS, Faraz Q, Al-Dubai SAR, Vohra F, Abdullah H, Taiyeb-Ali TB, et al. Clinical outcomes and predictors of satisfaction in patients with improved lithium disilicate all-ceramic crowns. Med Princ Pract. 2017;26(5):470-9. doi: $10.1159 / 000481864$.

17. Nazari V, Ghodsi S, Alikhasi M, Sahebi M, Shamshiri AR. Fracture strength of three-unit implant supported fixed partial dentures with excessive crown height fabricated from different materials. J Dent (Tehran). 2016 Nov;13(6):400-6.

18. Taufall S, Eichberger M, Schmidlin PR, Stawarczyk B. Fracture load and failure types of different veneered polyetheretherketone fixed dental prostheses. Clin Oral Investig. 2016 Dec;20(9):2493-500. doi:10.1007/ s00784-016-1777-4.

19. Abdullah $\mathrm{A} 0$, Tsitrou EA, Pollington $\mathrm{S}$. Comparative in vitro evaluation of CAD/CAM vs conventional provisional crowns. J Appl Oral Sci. 2016 MayJun;24(3):258-63. doi:10.1590/1678-775720150451.

20. Jin HY, Teng MH, Wang ZJ, Li X, Liang JY, Wang WX, Jiang S, Zhao BD Comparative evaluation of BioHPP and titanium as a framework veneered with composite resin for implant-supported fixed dental prostheses. J Prosthet Dent. 2019 0ct;122(4):383-8. doi: 10.1016/.jprosdent.2019.03.003.

21. Hossam M, Waleed E, Masoud GE. Evaluation of Marginal adaptation and fracture resistancE of BioHpp and Zirconia. Egypt Dent J. 2019;64(3):14891501.

22. Lee YK, Lu H, Oguri M, Powers JM. Changes in color and staining of dental composite resins after wear simulation. J Biomed Mater Res B Appl Biomater. 2007 Aug;82(2):313-9. doi: 10.1002/jbm.b.30735. 
23. Bahadır HS, Bayraktar Y. Evaluation of the repair capacities and color stabilities of a resin nanoceramic and hybrid CAD/CAM blocks. J Adv Prosthodont. 2020 Jun;12(3):140-9. doi:10.4047/jap.2020.12.3.140.
24. Zoidis P,Papathanasiou I,Polyzois G. The use of a modified poly-ether-etherketone (peek) as an alternative framework material for removable dental prostheses. A clinical report. J Prosthodont. 2016 0ct;25(7):580-4. doi: 10.1111/ jopr.12325.

\section{Abdelrahman S Badran \\ (Corresponding address)}

Faculty of Dentistry - Cairo University - Cairo, Egypt.

Email: asbadran77@gmail.com 